\title{
Antipsychotic prescribing for Alzheimer's disease and related disorders in specialized settings from 2010 to 2014 in France: a repeated cross-sectional study
}

Karim Tifratene ${ }^{1,2}$, Valeria Manera ${ }^{1}$, Roxane Fabre ${ }^{1,2}$, Auriane Gros ${ }^{1,3}$, Susanne Thummler ${ }^{1}$, Christian Pradier ${ }^{2}$, Philippe Robert ${ }^{1,3}$ and Renaud David ${ }^{1,3,4^{*}}$

\begin{abstract}
Background: Safety warnings from health authorities are currently intended to limit the use of antipsychotics (APs) in dementia-related conditions to treat neuropsychiatric symptoms, such as disturbing and/or delusional behaviors. The aim of this study is to investigate prevalence, correlates and trends of AP prescribing among people with dementia between 2010 and 2014 in the French population.

Methods: AP prescribing and associated factors among individuals with $A D$, mixed dementia and vascular dementia in the French National Alzheimer Database between 2010 and 2014 were analyzed using multivariate generalized estimating equations models ( $n=199,549)$.

Results: In 2014, 7.7\% of people with dementia were prescribed an AP. Compared with 2010 there was a 16\% increase in AP use. Multivariate analysis showed a linear increase risk of prescription with an adjusted odds ratio (95\% confidence interval) of 1.23 (1.17-1.30) in 2014 compared with 2010. Factors associated with AP prescribing were male gender, more severe cognitive decline and living in long-term care facilities. Older age and higher education were protective toward AP prescribing. The type of dementia did not have any influence on AP prescribing.

Conclusion: An increase in AP prescribing among individuals with dementia in French specialized settings over the last 5 years occurred despite safety warnings. This phenomenon suggests that alternative solutions for the management of behavioral and psychiatric symptoms in these populations are still urgently needed.
\end{abstract}

Keywords: Dementia, Alzheimer's disease, Antipsychotics, Drug prescribing, French Alzheimer Database

\section{Background}

Behavioral and psychological symptoms of dementia (BPSD), also known as neuropsychiatric symptoms, affect more than $90 \%$ of individuals during the course of Alzheimer's disease (AD) [1], and are also very common in other neurodegenerative diseases. The management of BPSD is challenging and specific pharmacological and nonpharmacological approaches have been proposed [2].

\footnotetext{
* Correspondence: david.r@chu-nice.fr

${ }^{1}$ EA Cobtek, University of Nice Sophia-Antipolis, Nice, France

${ }^{3}$ Research and Resources Memory Centre, Nice University Hospital, Nice, France

Full list of author information is available at the end of the article
}

Antipsychotic (AP) prescribing has frequently been recognized as a last-resort solution in order to manage disturbing symptoms such as aggression and agitation, and psychotic symptoms such as delirium and hallucinations [3]. There is a general lack of evidence about AP efficacy in older people with dementia and about risks of serious adverse events, including short and long-term increased mortality rates [4-6]. Conventional AP drugs can cause extrapyramidal syndrome and tardive dyskinesia [7]. The use of atypical AP drugs can lead to acute and subacute side effects, in particular sedation, postural hypotension and falls, especially at high doses. AP use is associated with greater severity of dementia and poorer 
medical status [8], more rapid decline in global cognitive level, as well as increased neuropsychiatric symptoms [9].

Despite this, AP prescribing remains very common to reduce BPSD. APs remain likely overprescribed in longterm care facilities with limited alternative resources, and many older individuals receiving APs do often not fulfill prescription criteria approved by regulation authorities' guidelines [10]. High prevalence of AP use has been reported, in large cohorts, among older populations living in the community and in long-term care facilities, and concerning individuals diagnosed with and without dementia $[10,11]$.

The lack of evidence on AP efficacy in the management of BPSD and the numerous side effects translate at the regulatory approval level into no AP drug being approved for use in dementia in the USA, and only Risperidone is labeled in Europe, including France.

Excessive AP use in older populations with dementia has led several regulation authorities to publish safety warnings [11]. The impact of these warnings had been studied in different settings and most often showed a decrease, to various extents, in AP use among older individuals with and without dementia. For instance, a study in Finland reported decreased use of AP in nursing homes (between 2003 and 2011) from $42.6 \%$ to $27.8 \%$, associated with an increase from $26.9 \%$ to $32.0 \%$ in assisted living facilities (between 2007 and 2011), with a similar trend regarding the mean number of psychotropic medications (AP, antidepressants, anxiolytics and hypnotics) [12]. In the USA, regulatory warnings regarding the use of atypical AP in the management of dementiarelated conditions showed minimal impact in noninstitutionalized populations, with a compensatory shift in favor of benzodiazepines and anti-dementia medications [13]. However, another initiative in the USA allowed a $12 \%$ decrease (from $21.3 \%$ to $18.7 \%$ ) in AP use in nursing homes between 2012 and 2013 [14]. In France, AP use decreased in the older population between 2003 and 2011, especially in persons with dementia (from $14.2 \%$ to $10.2 \%$ ) [11]. The timing of the decrease, however, did not coincide with safety warning publications.

AP prescribing in individuals with dementia is still debated and recently the American Psychiatric Association issued guidelines focusing 'on the judicious use of AP medications when agitation or psychosis occurs in association with dementia' [15]. New evidence shows that an increased risk of death after AP prescribing is present for individuals with and without dementia, with a more pronounced risk in control participants without dementia than in individuals with dementia [16]. Moreover, despite most studies agreeing on the drawbacks of AP, a real benefit in the management of BPSD seems to exist for the more advanced symptomatic stages of dementia [17]. In this context, and taking into account that no major advancements in the treatment of BPSD in dementia occurred in the last decade and that practitioners have, in general, limited knowledge and/or access to alternative, nonpharmacological solutions in BPSD management [18], we hypothesized that the prevalence of use of AP prescribing in demented patients is not decreasing.

The aim of the present study was to evaluate the annual prevalence of AP prescribing in individuals with $\mathrm{AD}$ and related disorders in France between 2010 and 2014. We additionally explored sociodemographic and clinical factors associated with the use of AP.

\section{Methods}

\section{French National Alzheimer Database (Banque Nationale Alzheimer)}

The Banque Nationale Alzheimer (BNA) is part of the French strategy to fight against dementia [19-21] and records information since the end of 2009. The aim of this database is to provide information about the medical activity of French memory centers in order to adapt the healthcare provision and to generate epidemiologic knowledge on the diseases and medical practices. Information collected in the BNA consists of a limited set of data concerning demographic, diagnostic and clinical data selected by a national consensus group. The number of variables was restricted to facilitate and enhance care providers participating in this national database. Data are collected from 427 French memory units-399 memory centers (local level) and 28 resource and research memory centers (regional level)-and from 61 independent neurologists who expressed a willingness to participate.

Each time a patient consults a center, a record is generated and transferred to the database. Therefore, one patient can figure more than once in the BNA, depending on the number of medical acts he/she underwent.

Variables used for this study are: gender, age, living conditions, education, type of center, referring modalities, location of the patient, Mini Mental Score Examination (MMSE) [22], date of consultation, diagnosis and treatments. The BNA differentiates 38 diagnostic groups, based on the ICD-10 classification. Code F00.1 relates to $\mathrm{AD}$, code F00.2 to mixed dementia (MD) and code F01.9 is used for vascular dementia (VD). For treatments, the BNA records the presence of a prescription at the time of the consultation for six groups of psychotropic drugs classified as follows, using ATC codes: antidepressant (N06A), anxiolytic (N05B), hypnotic (N05C), antipsychotic (N05A), cholinesterase inhibitors (ChEIs) (N06DA) and N-Methyl-D-aspartate receptor antagonist (NMDA antagonist) (N06DX01). No data are available on drug generics or brand names, nor on dosage. More details on this database are described elsewhere [23]. 


\section{Study design and subject selection}

A repeated cross-sectional study was conducted using data from the BNA from January 1, 2010 to December 31,2014 . Only individuals who received one of the three diagnoses of interest (AD (F00.1), MD (F00.2) and VD (F01.9)) (among the 38 diagnostic groups available in the BNA) at least once during the study timeframe were included in the analysis. Individuals receiving prescriptions of anti-AD agents without an associated $\mathrm{AD}$ diagnosis were not considered for the analysis, as well as individuals with any other ICD-10 diagnosis such as major depressive disorder (F33), psychosis (F29) and anxiety-related disorders (F40, F41, F42, F43).

A single patient could have different entries in different years of study, corresponding to different consultations. To describe the whole population included in the study, we selected the first diagnosis attributed to the patient within the study period. We adopted the same rule to describe the population according to the year of consultation; so if an individual had two or more different diagnoses between 2010 and 2014 then the first was systematically considered. Similarly, if patients were assigned different scores for the MMSE tests during the period of interest (single year or 5-year period), the first MMSE was systematically considered for the descriptive analysis. Given the importance of cognitive status, only patients with at least one existing MMSE evaluation were considered in the analysis.

Because the event of interest for the study is drug prescribing, if an individual was prescribed an AP at any time during 1 year then this person was considered "under treatment" during this year. This status was reviewed each year.

\section{Statistical analysis}

Descriptive analyses were conducted using percentages. Age and MMSE scores (quantitative variables) were categorized according to the distribution observed. Annual prevalence of AP prescribing was calculated as the number of patients with at least one prescription of AP during the year divided by the number of patients with one of the three diagnoses of interest seen during the same year (an individual can only appear once in the numerator and once in the denominator). The Cochrane Armitage test for trend was used to assess a linear evolution of the annual prevalence rate of AP prescriptions between 2010 and 2014.

To analyze factors associated with AP prescribing, we performed regression analyses including time-independent variables (gender, education, referring modality, diagnosis) and time-dependent variables (age, type of center, MMSE, neuroleptic, hypnotic, anxiolytic, NMDA antagonist, ChEIs, lifestyle). To account for the correlation between repeated measurements on the same individual (the same patient can have several consultations over the period, and thus several data entries), we used a logistic regression with generalized estimating equations (GEE) method.

All variables significantly associated with AP prescribing in univariate GEE models with a $p$-value threshold under 0.05 where included in multivariate GEE models. A backward stepwise elimination approach was used and only variables still significantly associated with the outcome variable with $p<0.05$ were kept in the final model. In order to take into account an effect of time on the covariables, we tested all second-order interactions concerning the variable "year of consultation". Significant interactions were included in the final model. Adjusted odds ratios (adj. ORs) are presented with the $95 \%$ confidence interval.

All tests were performed bilaterally. Statistical analyses were carried out with SAS Enterprise Guide software, version 5.1 (SAS Inc., Cary, NC, USA).

\section{Results}

Between 2010 and 2014, 223,073 individuals with a diagnosis of $\mathrm{AD}, \mathrm{MD}$ or $\mathrm{VD}$ consulted one of the BNA centers. Among these, 199,549 individuals (mean (SD) age: 81.72 (7.50); median (IQR) age: 82.66 (78.01; 86.62)) were considered for analysis because they had at least one global cognitive evaluation using the MMSE over the period (mean of 1.7 consultations) (Fig. 1). The number of patients who consulted the BNA network increased from 40,781 patients in 2010 to 77,866 in 2014.

Demographic characteristics of the study population according to the diagnosis are presented in Table 1. The population of individuals with dementia was diagnosed mainly as $\mathrm{AD}(65.4 \%)$, followed by MD (23.7\%) and VD (10.9\%). Most individuals with dementia were female (66.7\%), living in the community (83.9\%), addressed by the GP $(65.9 \%)$ and had a primary or lower education level (58.5\%). Compared with $\mathrm{AD}$ and $\mathrm{MD}$, individuals with VD appeared to more often be males, with a less advanced cognitive decline measured by MMSE and more frequently referred by a specialist.

Among all diagnostic subgroups, 17,754 individuals (8.9\%) were prescribed an AP at least once in the 5-year period. Annual prevalence of AP use significantly increased in a linear manner from $6.5 \%$ to $7.7 \%$ between 2010 and $2014\left(p<10^{-5}\right)$ (Table 2). This increase was observed for community-dwelling individuals and longterm care facilities (Additional file 1).

Considering individuals who received at least one AP prescribing, around $70 \%$ were prescribed $\mathrm{AP}$ with another psychotropic medication. The most frequent concomitant prescribing was AP + antidepressant with a stable proportion over the period (around 21\%). A quarter of the patients were prescribed AP with two other psychotropic drugs. Among individuals receiving at least one AP medication, a third received a NMDA antagonist and half 


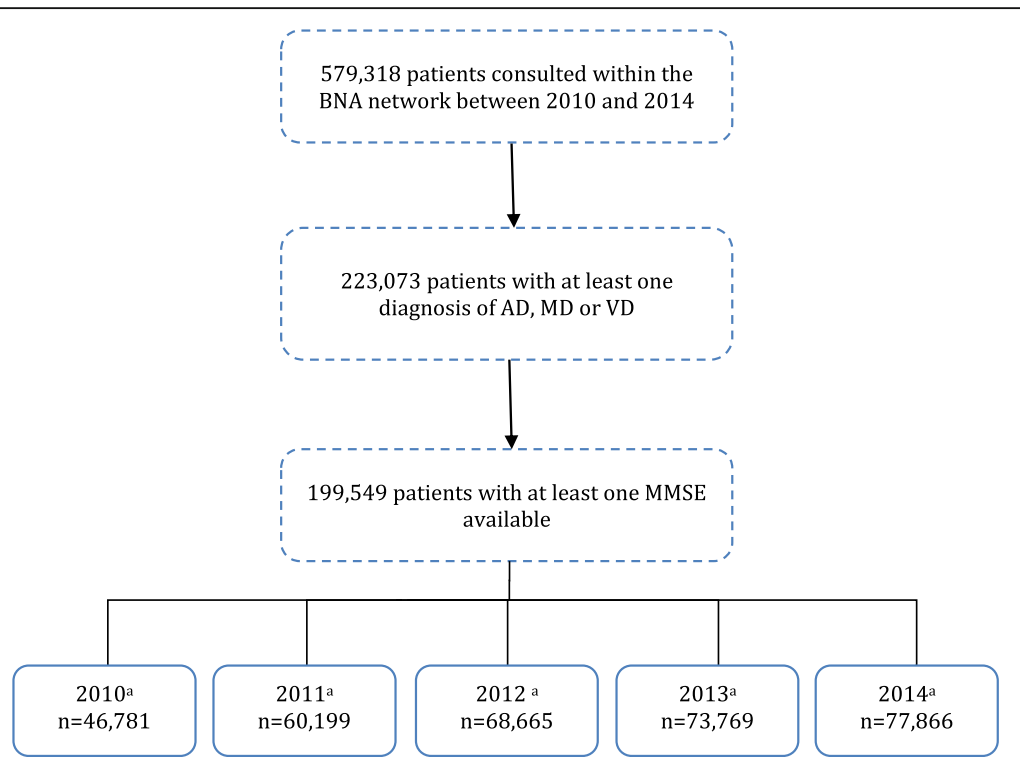

Fig. 1 Selection of participants included in the study. ${ }^{a}$ The same individual could account for different years. When considering a single year, an individual can only be counted once. AD Alzheimer's disease, BNA Banque Nationale Alzheimer, MD mixed dementia, MMSE Mini Mental State Examination, VD vascular dementia

received a ChEI, with a progressive decrease from 2010 to 2013 followed by an increase as of 2014.

Table 3 presents the adj. ORs estimated by the final logistic multivariate GEE model for AP prescribing. The increase in AP prescribing between 2010 and 2014 was confirmed in multivariate analysis with an adj. OR (95\% confidence interval) of $1.2(1.17-1.30)$ in 2014 compared with 2010. There was a systematic significant increase of the adj. OR for the next year independently of the year of reference chosen in the model (results not shown). There was a gradual increased risk of AP prescribing with lower MMSE scores. Male gender and living in long-term care facilities were also associated with an increased risk of AP prescription. Additionally, the use of any other type of psychotropic drugs or anti-dementia agents (except for ChEIs) was an associated factor of AP prescribing. Older age and high educational levels were protective against the risk of AP prescription. Compared with individuals treated in memory clinics, individuals in regional reference memory clinics and individuals treated by private practice neurologists were less likely to receive an AP drug.

An interaction between type of center and time was found to be significant $(p<0.001)$ and was kept in the final multivariate model. This showed that AP prescribing levels increased more in regional centers than in memory clinics over time while the use of AP did not vary significantly between 2010 and 2014 for independent neurologists. The type of dementia (AD, VD or $\mathrm{MD}$ ) did not significantly influence AP prescribing.

\section{Discussion}

In this large study based on the French National Alzheimer Database, the annual prevalence of AP prescribing among individuals with dementia slightly increased from $6.5 \%$ in 2010 to $7.7 \%$ in 2014 despite safety warnings issued in France (as well as in Europe and in the USA). This trend was confirmed in the multivariate analysis with a constant increased risk of prescription over time.

\section{Prevalence of AP use and associated factors}

Our results regarding prevalence of AP use are consistent with previous studies among individuals with dementia [24-27], whereas other authors reported much higher rates of AP use [12, 28-32]. The settings of the present analysis may explain some of the observed discrepancies. First, most individuals were living in the community at a stage of the disease at which psychiatric symptoms do not yet imply long-term institutionalization, which may explain lower AP prescribing [33]. Second, the study took place in specialized settings where specialists are often able to propose nonpharmacological treatments for BPSD, and this could reduce the use of AP. This is illustrated by the fact that, in this study, an individual treated in a regional center rather than a local center has a lower chance of receiving an AP, probably because nonpharmacological approaches are more developed in reference centers. Third, several authors also included the presence of delirium or psychotic conditions as inclusion criteria likely leading to AP use. We decided not to include individuals with 'psychotic disorders' as a main diagnosis 
Table 1 Descriptive characteristics by type of dementia

\begin{tabular}{|c|c|c|c|c|c|c|c|c|}
\hline \multirow{3}{*}{ Follow-up time (years), mean (SD) } & \multicolumn{2}{|c|}{$\begin{array}{l}\text { All } \\
(n=199,549)\end{array}$} & \multicolumn{2}{|c|}{$\begin{array}{l}\text { Alzheimer disease } \\
(n=130,442)\end{array}$} & \multicolumn{2}{|c|}{$\begin{array}{l}\text { Mixed dementia } \\
(n=47,320)\end{array}$} & \multicolumn{2}{|c|}{$\begin{array}{l}\text { Vascular dementia } \\
(n=21,787)\end{array}$} \\
\hline & 0.87 & $(1.18)$ & 0.94 & $(1.21)$ & 0.83 & $(1.16)$ & 0.55 & (0.96) \\
\hline & $n$ & (\%) & $n$ & $(\%)$ & $n$ & (\%) & $n$ & (\%) \\
\hline \multicolumn{9}{|l|}{ Year of first consultation } \\
\hline 2010 & 47,624 & (23.9) & 32,900 & $(25.2)$ & 10,831 & (22.9) & 3,893 & (17.9) \\
\hline 2011 & 37,236 & $(18.7)$ & 24,925 & $(19.1)$ & 8,565 & $(18.1)$ & 3,746 & $(17.2)$ \\
\hline 2012 & 37,521 & (18.8) & 24,367 & $(18.7)$ & 8,894 & (18.8) & 4,260 & (19.6) \\
\hline 2013 & 37,902 & $(19.0)$ & 24,175 & (18.5) & 9,060 & $(19.2)$ & 4,667 & (21.4) \\
\hline 2014 & 39,266 & $(19.7)$ & 24,075 & $(18.5)$ & 9,970 & $(21.1)$ & 5,221 & (24.0) \\
\hline \multicolumn{9}{|l|}{ Age at first consultation with the diagnosis } \\
\hline$\leq 75$ years & 29,250 & $(14.7)$ & 20,818 & $(16.0)$ & 4,717 & $(10.0)$ & 3,715 & (17.1) \\
\hline $76-80$ years & 39,887 & (20.0) & 26,459 & (20.3) & 9,001 & $(19.0)$ & 4,427 & (20.3) \\
\hline $81-85$ years & 61,481 & (30.8) & 39,853 & (30.6) & 15,279 & (32.3) & 6,349 & $(29.1)$ \\
\hline$>85$ years & 68,931 & $(34.5)$ & 43,312 & (33.2) & 18,323 & $(38.7)$ & 7,296 & (33.5) \\
\hline \multicolumn{9}{|l|}{ Gender } \\
\hline Female & 133,102 & $(66.7)$ & 91,538 & $(70.2)$ & 29,493 & (62.3) & 12,071 & $(55.4)$ \\
\hline Male & 66,447 & (33.3) & 38,904 & (29.8) & 17,827 & $(37.7)$ & 9,716 & (44.6) \\
\hline \multicolumn{9}{|l|}{ Education (years) } \\
\hline 0 & 15,955 & $(8.0)$ & 10,351 & (7.9) & 3,750 & (7.9) & 1,854 & $(8.5)$ \\
\hline $1-5$ & 100,745 & (50.5) & 64,068 & $(49.1)$ & 25,527 & (54.0) & 11,150 & $(51.2)$ \\
\hline $6-12$ & 48,163 & $(24.1)$ & 31,965 & (24.5) & 10,809 & (22.8) & 5,389 & $(24.7)$ \\
\hline$\geq 13$ & 14,358 & $(7.2)$ & 9,955 & (7.6) & 2,932 & (6.2) & 1,471 & $(6.8)$ \\
\hline Unknown & 20,328 & $(10.2)$ & 14,103 & (10.8) & 4,302 & (9.1) & 1,923 & (8.8) \\
\hline \multicolumn{9}{|l|}{ Type of centre } \\
\hline Memory clinic & 150,404 & (75.4) & 96,381 & (73.9) & 37,242 & (78.7) & 16,781 & (77.0) \\
\hline Regional specialized memory clinic & 43,951 & (22.0) & 30,138 & $(23.1)$ & 9,136 & $(19.3)$ & 4,677 & (21.5) \\
\hline Private practice neurologist & 5,194 & (2.6) & 3,923 & (3.0) & 942 & $(2.0)$ & 329 & $(1.5)$ \\
\hline \multicolumn{9}{|l|}{ Initially referred by } \\
\hline GP & 131,589 & (65.9) & 89,445 & (68.6) & 30,141 & $(63.7)$ & 12,003 & $(55.1)$ \\
\hline Neurologist & 9,564 & $(4.8)$ & 6,637 & (5.1) & 1,702 & (3.6) & 1,225 & (5.6) \\
\hline Other specialist & 22,240 & $(11.2)$ & 13,016 & $(10.0)$ & 5,996 & $(12.7)$ & 3,228 & (14.8) \\
\hline Direct & 8,499 & $(4.3)$ & 6,077 & $(4.7)$ & 1,733 & $(3.7)$ & 689 & (3.2) \\
\hline Others & 27,657 & $(13.9)$ & 15,267 & $(11.7)$ & 7,748 & $(16.4)$ & 4,642 & (21.3) \\
\hline \multicolumn{9}{|l|}{ Lifestyle at baseline } \\
\hline Community-living & 167,324 & (83.9) & 111,034 & $(85.1)$ & 38,602 & (81.6) & 17,688 & $(81.2)$ \\
\hline Long-term care facility & 32,225 & $(16.2)$ & 19,408 & (14.9) & 8,718 & (18.4) & 4,099 & (18.8) \\
\hline \multicolumn{9}{|l|}{ Location of the patient at baseline } \\
\hline Within $50 \mathrm{~km}$ from the memory clinic & 184,381 & (92.4) & 119,769 & (91.8) & 44,323 & $(93.7)$ & 20,289 & (93.1) \\
\hline$>50 \mathrm{~km}$ from the memory clinic & 15,168 & (7.6) & 10,673 & $(8.2)$ & 2,997 & (6.3) & 1,498 & $(6.9)$ \\
\hline \multicolumn{9}{|l|}{ MMSE at first record } \\
\hline $0-10$ & 26,451 & $(13.3)$ & 19,074 & (14.6) & 5,585 & $(11.8)$ & 1,792 & $(8.2)$ \\
\hline $11-20$ & 102,300 & (51.3) & 66,727 & $(51.2)$ & 25,916 & (55.8) & 9,657 & (44.3) \\
\hline $21-30$ & 70,798 & (35.5) & 44,641 & (34.2) & 15,819 & (33.4) & 10,338 & $(47.5)$ \\
\hline \multicolumn{9}{|c|}{ At least one antipsychotic prescribing between 2010 and 2014} \\
\hline No & 181,795 & $(91.1)$ & 118,685 & $(91.0)$ & 43,089 & $(91.1)$ & 20,021 & (91.9) \\
\hline Yes & 17,754 & $(8.9)$ & 11,757 & (9.0) & 4,231 & (8.9) & 1,766 & $(8.1)$ \\
\hline
\end{tabular}

MMSE Mini Mental State Examination 
Table 2 Prevalence of antipsychotic prescribing and concomitant psychotropic medications across years from 2010 to 2014

\begin{tabular}{|c|c|c|c|c|c|c|c|c|c|c|c|}
\hline & & \multicolumn{2}{|l|}{2010} & \multicolumn{2}{|l|}{2011} & \multicolumn{2}{|l|}{2012} & \multicolumn{2}{|l|}{2013} & \multicolumn{2}{|l|}{2014} \\
\hline & & $n$ & (\%) & $n$ & $(\%)$ & $n$ & (\%) & $n$ & $(\%)$ & $n$ & $(\%)$ \\
\hline \multicolumn{12}{|c|}{ At least one antipsychotic prescribing } \\
\hline \multirow[t]{3}{*}{ Overall } & No & 43,742 & $(93.5)$ & 55,898 & $(92.9)$ & 63,758 & $(92.9)$ & 68,369 & $(92.7)$ & 71,853 & (92.3) \\
\hline & Yes & 3,039 & (6.5) & 4,301 & $(7.1)$ & 4,907 & $(7.2)$ & 5,400 & $(7.3)$ & 6,013 & $(7.7)$ \\
\hline & Total & 46,781 & & 60,199 & & 68,665 & & 73,769 & & 77,866 & \\
\hline \multirow[t]{3}{*}{ Alzheimer's disease } & No & 30,123 & $(93.4)$ & 38,513 & $(92.9)$ & 43,454 & $(93.0)$ & 45,857 & (92.8) & 47,180 & (92.4) \\
\hline & Yes & 2,146 & $(6.7)$ & 2,954 & $(7.1)$ & 3,276 & $(7.0)$ & 3,549 & $(7.2)$ & 3,871 & (7.6) \\
\hline & Total & 32,269 & & 41,467 & & 46,730 & & 49,406 & & 51,051 & \\
\hline \multirow[t]{3}{*}{ Mixed dementia } & No & 10,011 & $(93.8)$ & 12,669 & $(92.6)$ & 14,599 & $(92.5)$ & 15,928 & (92.5) & 17,208 & (92.0) \\
\hline & Yes & 661 & $(6.2)$ & 1,006 & $(7.4)$ & 1,184 & $(7.5)$ & 1,299 & $(7.5)$ & 1,491 & (8.0) \\
\hline & Total & 10,672 & & 13,675 & & 15,783 & & 17,227 & & 18,699 & \\
\hline \multirow[t]{3}{*}{ Vascular dementia } & No & 3,608 & $(94.0)$ & 4,716 & $(93.3)$ & 5,705 & $(92.7)$ & 6,584 & (92.3) & 7,465 & (92.0) \\
\hline & Yes & 232 & (6.0) & 341 & $(6.7)$ & 447 & $(7.3)$ & 552 & $(7.7)$ & 651 & (8.0) \\
\hline & Total & 3,840 & & 5,057 & & 6,152 & & 7,136 & & 8,116 & \\
\hline \multicolumn{12}{|c|}{ Psychotropic associations among patients receiving at least one antipsychotic prescribing } \\
\hline \multicolumn{2}{|l|}{ Antipsychotic only } & 1,002 & $(33.0)$ & 1,248 & $(29.0)$ & 1,471 & $(30.0)$ & 1,676 & (31.0) & 1,722 & (28.6) \\
\hline \multicolumn{2}{|l|}{ Antipsychotic + hypnotic } & 153 & $(5.0)$ & 174 & $(4.1)$ & 217 & $(4.4)$ & 215 & $(4.0)$ & 205 & (3.4) \\
\hline \multicolumn{2}{|c|}{ Antipsychotic + hypnotic + antidepressant } & 134 & $(4.4)$ & 208 & $(4.8)$ & 192 & (3.9) & 215 & $(4.0)$ & 228 & (3.8) \\
\hline \multicolumn{2}{|c|}{ Antipsychotic + antidepressant } & 639 & $(21.0)$ & 976 & $(22.7)$ & 1,07 & $(21.8)$ & 1,142 & $(21.2)$ & 1,285 & (21.4) \\
\hline \multicolumn{2}{|l|}{ Antipsychotic + anxiolytic } & 377 & $(12.4)$ & 531 & $(12.4)$ & 619 & $(12.6)$ & 680 & (12.6) & 739 & (12.3) \\
\hline \multicolumn{2}{|c|}{ Antipsychotic + anxiolytic + hypnotic } & 106 & $(3.5)$ & 125 & $(2.9)$ & 148 & (3.0) & 172 & $(3.2)$ & 202 & (3.4) \\
\hline \multicolumn{2}{|c|}{ Antipsychotic + anxiolytic + antidepressant } & 463 & $(15.2)$ & 767 & $(17.8)$ & 895 & $(18.2)$ & 982 & $(18.2)$ & 1,222 & (20.3) \\
\hline \multicolumn{2}{|c|}{ Antipsychotic + anxiolytic + hypnotic + antidepressant } & 165 & $(5.4)$ & 272 & $(6.3)$ & 295 & $(6.0)$ & 318 & $(5.9)$ & 410 & (6.8) \\
\hline \multicolumn{12}{|c|}{ Anti-dementia agents among patients receiving at least one antipsychotic prescribing } \\
\hline \multirow[t]{2}{*}{ NMDA antagonist } & No & 1,756 & $(57.8)$ & 2,865 & $(66.6)$ & 3,556 & $(72.5)$ & 3,981 & (73.7) & 3,933 & $(65.4)$ \\
\hline & Yes & 1,283 & $(42.2)$ & 1,436 & $(33.4)$ & 1,351 & $(27.5)$ & 1,419 & (26.3) & 2,080 & (34.6) \\
\hline \multirow[t]{2}{*}{ ChEl } & No & 1,433 & $(47.2)$ & 1,981 & $(46.1)$ & 2,588 & $(52.7)$ & 3,323 & $(61.5)$ & 3,443 & (57.3) \\
\hline & Yes & 1,606 & $(52.9)$ & 2,320 & $(53.9)$ & 2,319 & $(47.3)$ & 2,077 & (38.5) & 2,570 & $(42.7)$ \\
\hline \multirow[t]{3}{*}{ ChEl + NMDA antagonist } & No & 2,473 & $(81.4)$ & 3,616 & 84.1 & 4,345 & $(88.6)$ & 4,946 & (91.6) & 5,227 & $(86.9)$ \\
\hline & Yes & 566 & $(18.6)$ & 685 & 15.9 & 562 & $(11.4)$ & 454 & (8.4) & 786 & $(13.1)$ \\
\hline & Total & 3,039 & & 4,301 & & 4,907 & & 5,400 & & 6,013 & \\
\hline
\end{tabular}

in our analysis whereas this ICD-10 diagnosis is also available in the BNA. Finally, the use of AP may vary across countries and different health systems, as shown in de Mauleon et al.'s study [34] investigating AP prescribing among individuals with dementia recently admitted to long-term care facilities in eight European countries, with prevalence ranging from $12 \%$ in Sweden to $54 \%$ in Spain (with an average use of $37.4 \%$, and France at $26.5 \%$ being the second least prescribing country after Sweden).

In the present study, several factors significantly associated with AP use have been identified. One of the main factors was cognitive decline as measured here with the MMSE score and known to be associated with BPSD and with an increased risk of AP prescribing [8, 25, 35]. Younger age, male gender and institutionalization are also risk factors associated with increased AP prescribing [25]. Higher education was associated with a lower probability of AP use, with adj. OR decreasing as the educational level increased. This finding has already been reported in recent studies [36] and can have several explanatory hypotheses: a differential expression of symptoms in highly educated versus less educated individuals; a preference for nonpharmacological treatments expressed by the family of highly educated patients [37]; and, finally, the possibility of an adaptation of the physician's attitude to the educational level of the patient and their family. 
Table 3 Determinants of antipsychotic prescribing using multivariate logistic GEE estimation $(N=199,549)$

\begin{tabular}{|c|c|c|c|}
\hline & $\begin{array}{l}\text { Adjusted } \\
\text { odds ratio }\end{array}$ & $\begin{array}{l}95 \% \text { confidence } \\
\text { interval }\end{array}$ & $p$ value \\
\hline \multicolumn{4}{|l|}{ Year } \\
\hline 2010 & 1 & & \\
\hline 2011 & 1.10 & $1.05-1.15$ & $<0.001$ \\
\hline 2012 & 1.12 & $1.06-1.17$ & $<0.001$ \\
\hline 2013 & 1.16 & $1.10-1.21$ & $<0.001$ \\
\hline 2014 & 1.23 & $1.17-1.30$ & $<0.001$ \\
\hline \multicolumn{4}{|l|}{ MMSE } \\
\hline $0-10$ & 2.63 & $2.51-2.75$ & $<0.001$ \\
\hline $11-20$ & 1.56 & $1.51-1.62$ & $<0.001$ \\
\hline $21-30$ & 1 & & \\
\hline \multicolumn{4}{|c|}{ Age at first consultation with the diagnosis } \\
\hline$\leq 75$ years & 1 & & \\
\hline $76-80$ years & 0.91 & $0.86-0.96$ & 0.001 \\
\hline $81-85$ years & 0.85 & $0.81-0.90$ & $<0.001$ \\
\hline$>85$ years & 0.80 & $0.76-0.84$ & $<0.001$ \\
\hline \multicolumn{4}{|l|}{ Gender } \\
\hline Female & 1 & & \\
\hline Male & 1.34 & $1.30-1.39$ & $<0.001$ \\
\hline \multicolumn{4}{|l|}{ Education (years) } \\
\hline 0 & 1 & & \\
\hline $1-5$ & 0.87 & $0.82-0.92$ & $<0.001$ \\
\hline $6-12$ & 0.84 & $0.78-0.89$ & $<0.001$ \\
\hline$\geq 13$ & 0.77 & $0.70-0.84$ & $<0.001$ \\
\hline Unknown & 0.96 & $0.89-1.03$ & 0.224 \\
\hline \multicolumn{4}{|l|}{ Type of centre } \\
\hline Memory clinic & 1 & & \\
\hline $\begin{array}{l}\text { Regional reference memory } \\
\text { centre }\end{array}$ & 0.83 & $0.77-0.91$ & $<0.001$ \\
\hline Private practice neurologist & 0.60 & $0.42-0.86$ & 0.006 \\
\hline \multicolumn{4}{|l|}{ Antidepressant } \\
\hline No & 1 & & \\
\hline Yes & 1.77 & $1.71-1.84$ & $<0.001$ \\
\hline \multicolumn{4}{|l|}{ Hypnotic } \\
\hline No & 1 & & \\
\hline Yes & 1.91 & $1.82-2.01$ & $<0.001$ \\
\hline \multicolumn{4}{|l|}{ Anxiolytic } \\
\hline No & 1 & & \\
\hline Yes & 2.42 & $2.33-2.51$ & $<0.001$ \\
\hline \multicolumn{4}{|l|}{ NMDA antagonist } \\
\hline No & 1 & & \\
\hline Yes & 1.32 & $1.28-1.36$ & $<0.001$ \\
\hline
\end{tabular}

Table 3 Determinants of antipsychotic prescribing using multivariate logistic GEE estimation ( $N=199,549)$ (Continued)

\begin{tabular}{llll}
\hline Lifestyle & & & \\
Community-living & 1 & $1.94-2.09$ & $<0.001$ \\
Long-term care facility & 2.01 & & \\
Patient's location & & & \\
$\quad \begin{array}{l}\text { Within } 50 \mathrm{~km} \text { from memory } \\
\text { Consultation }\end{array}$ & & \\
$>50 \mathrm{~km}$ from memory & 0.93 & $0.87-1.00$ & \\
consultation & & \\
Years $\times$ type of center ${ }^{\mathrm{a}}$ & & \\
\hline $\begin{array}{l}\text { GEE generalized estimating equations, MMSE Mini Mental state examination, } \\
\text { NMDA N-methyl-D-aspartate receptor } \\
\text { aSignificant interaction entered in the model }\end{array}$
\end{tabular}

Among patients with AP prescribing, about $70 \%$ were exposed to concomitant drug prescribing. Multiple psychotropic exposures in older populations with and without dementia have been widely described [38, 39] and raise the question of the appropriateness of these concomitant uses.

The etiology of dementia did not appear to be predictive of AP use. Furthermore, we did not find any decreased risk of AP prescribing for VD, likely due to the cardiovascular side effects of AP, as described elsewhere [8].

\section{Evolution of AP use between 2010 and 2014}

Despite the safety warnings for AP published by several regulation authorities including France in 2008 [11], we did not observe any significant decrease or stagnation in AP use in France between 2010 and 2014 among individuals diagnosed with $\mathrm{AD}, \mathrm{MD}$ and $\mathrm{VD}$. On the contrary, AP prescribing significantly increased to $15.6 \%$.

The different safety warnings issued by health authorities and medical associations worldwide in the last 15 years had different effects according to the context and the period studied. Some studies reported a decrease in AP prescribing $[11,40]$ while other studies showed an increase or stagnation in AP use [41, 42].

Given that our results were adjusted on several confounding factors including time-dependent variables (age, global cognitive level, psychotropic drug prescribing, social context) and time-independent variables (gender, education, type of dementia), some explanations relative to the scientific and regulatory environment of prescribing could be advanced. First, no major advance in the treatment of BPSD or dementia that could change the management of the patients occurred since the warnings were issued. Moreover, in France the conditions of the reimbursement of anti-AD symptomatic agents (ChEIs and NMDA antagonists) were restricted in 2011. Anti-AD agents could contribute to the management of BPSD, and their decreased use could have promoted the use of AP. Several authors have already 
investigated how AP prescribing could evolve before and after the initiation of ChEIs and NMDA antagonists. For instance, Lachaine et al. [43] have shown a significant difference in AP use when comparing pre-memantine and post-memantine initiation (with a significant lower increase in AP use after memantine initiation) among individuals with $A D$, whereas this phenomenon was not observed with ChEIs. A similar trend was described by Martinez et al. [44], with an observed decline in AP use after memantine initiation whereas AP prescribing continued to increase after ChEI initiation. In our study, we observed a global declining use of both ChEIs and memantine during the period, with memantine only significantly associated with an increased risk of AP prescribing. Second, the way health care providers received the warning could explain their lack of long-term efficacy. For instance, a study described that professional recommendations on drugs have less impact on specialists compared with nonspecialists [45]. This hypothesis should be considered because this study took place in a specialized setting. Third, as mentioned earlier, APs have a proven efficacy to control psychotic symptoms and seem to be useful for the more symptomatic subset of people with dementia, and withdrawal of APs is not recommended in these cases $[17,46]$.

\section{Limitations of the study}

Despite the size of the population and the 5 years of follow-up, several limitations should be noted.

First, the study period did not include a time before and after the date of the safety warning issued by the French Drug Agency (December 2008), so we cannot strictly assess the effect of the warning on AP prescribing. However, the trend we described is the opposite of what was expected only 2 years after the warnings. Second, the diagnoses in the BNA are entered by the physicians and reflect real life; it is thus possible that the different diagnoses are not based on the same criteria and this could introduce variability among diagnostic groups. Third, individuals included in the BNA are not fully representative of the total French population with $\mathrm{AD}$ and associated disorders; indeed, the BNA includes the great majority of people with $\mathrm{AD}$ and associated disorders who is referred to specialized centers (French memory units), but one part of the population with dementia is under GP supervision only (GPs do not have currently access to the BNA), and another part of the population is referred to specialists (geriatricians, neurologists, psychiatrists) from private practice who are not using the BNA database. Fourth, available information on AP medications in the BNA does not provide a highly complete set of information: for instance, the type of prescribed AP (i.e., first versus second generation), the drug name, the daily dose and the average treatment duration-which were all likely to change over time-were not available. Similarly, clinical reasons for and the context of treatment leading to AP prescriptions were not available in the BNA. Therefore we were not able to evaluate the appropriateness of the use of AP. Finally, we had no data on the effectiveness or tolerance of AP prescribing. We could therefore not assess whether the drug safety warnings had an impact in terms of drug-related risk minimization, which could be considered the final objective of the safety warnings rather than modifications of the prevalence of prescribing [47].

Future studies employing different databases or cohorts would be important to verify whether the observed trend of increased AP prescribing between 2010 and 2014 does extend to non-French populations with dementia, and whether similar results can be obtained with a patient population not referred to specialized memory centers. If the efficacy of safety warnings issued by health authorities in reducing AP use is controversial, some targeted educational interventions aimed at health care professionals and at a local level have shown a relative efficacy if provided regularly $[14,27]$.

\section{Conclusion}

An increase in AP prescribing among individuals with dementia in French specialized settings over the last years (in a linear manner from 6.5 to $7.7 \%$ between 2010 and 2014) occurred despite safety warnings. Lower MMSE scores, male gender and living in long-term care facilities were associated with an increased risk of AP prescription. The type of dementia (AD, VD or MD) did not significantly influence AP prescribing. This increase in AP prescribing suggests that alternative solutions for the management of behavioral and psychiatric symptoms in dementia are still urgently needed.

\section{Additional file}

Additional file 1: Prevalence of antipsychotic prescribing in the community and in long-term care facilities. (DOCX $49 \mathrm{~kb}$ )

\begin{abstract}
Abbreviations
AD: Alzheimer's disease; AP: Antipsychotic; BNA: Banque Nationale Alzheimer; BPSD: Behavioral and psychological symptoms in dementia; ChEl: Cholinesterase inhibitor; GEE: Generalized estimating equations; GP: General practitioner; MD: Mixed dementia; MMSE: Mini Mental State Examination; NMDA: N-Methyl-Daspartate receptor; VD: Vascular dementia
\end{abstract}

\section{Acknowledgements}

The authors thank all of the participating centers contributing to the BNA and Roland Chevrier for technical support.

Funding

The French National Alzheimer Database (Banque Nationale Alzheimer) is funded by the French Ministry of Health. 


\section{Availability of data and materials}

The BNA is a national database on Alzheimer's disease. Database extraction can be obtained on request to the data manager.

\section{Authors' contributions}

$\mathrm{KT}, \mathrm{VM}$ and RD participated in the design of the article, were involved in data synthesis and data interpretation, and drafted the manuscript. RF performed the statistical analysis. CP participated in the management of the database and helped in the statistical analysis and final revision of the manuscript. VM, AG and ST revised the final manuscript. PR was involved in the data interpretation, supervision and quality control of the BNA database and revised the final manuscript. All authors read and approved the final manuscript.

\section{Competing interests}

$P R, C P, S T, R F, A G, V M$ and $R D$ report no financial relationships with commercial interests. KT is currently an employee of Astrazeneca (oncology drug development) and was an employee of Glaxosmithkline in 2013 (urology and thrombosis drug development). VM declares that they have no competing interests.

\section{Consent for publication}

Not applicable.

\section{Ethics approval and consent to participate}

The study was conducted in accordance with the Declaration of Helsinki. According to the French law no consent was required because this study is based on an anonymous database. We checked the STROBE statement in drafting the article [48].

\section{Publisher's Note}

Springer Nature remains neutral with regard to jurisdictional claims in published maps and institutional affiliations.

\section{Author details}

${ }^{1}$ EA Cobtek, University of Nice Sophia-Antipolis, Nice, France. ${ }^{2}$ Department of Public Health, L'Archet Hospital, Nice University Hospital, Nice, France. ${ }^{3}$ Research and Resources Memory Centre, Nice University Hospital, Nice, France. ${ }^{4}$ Present address: Centre Mémoire de Ressources et de Recherche, Institut Claude Pompidou, 10 rue Molière, 06100 Nice, France.

Received: 11 November 2016 Accepted: 24 March 2017 Published online: 26 April 2017

\section{References}

1. Ballard CG, Gauthier S, Cummings $\mathrm{J}$, Brodaty $H$, Grossberg GT, Robert P, et al. Management of agitation and aggression associated with Alzheimer disease. Nat Rev Neurol. 2009:5(5):245-55.

2. Burns A, Ballard C. A best practice guide for health and social care professionals. London: Alzheimer's Society; 2013.

3. Bonner AF, Field TS, Lemay CA, Mazor KM, Andersen DA, Compher CJ, et al. Rationales that providers and family members cited for the use of antipsychotic medications in nursing home residents with dementia. J Am Geriatr Soc. 2015;63(2):302-8.

4. Langballe EM, Engdahl B, Nordeng H, Ballard C, Aarsland D, Selbaek G. Short- and long-term mortality risk associated with the use of antipsychotics among 26,940 dementia outpatients: a population-based study. Am J Geriatr Psychiatr. 2014;22(4):321-31.

5. Sink KM, Holden KF, Yaffe K. Pharmacological treatment of neuropsychiatric symptoms of dementia: a review of the evidence. JAMA. 2005;293(5):596-608.

6. Maust DT, Kim HM, Seyfried LS, Chiang C, Kavanagh J, Schneider LS, et al. Antipsychotics, other psychotropics, and the risk of death in patients with dementia: number needed to harm. JAMA Psychiat. 2015;72(5):438-45.

7. Foebel A, Ballokova A, Wellens NI, Fialova D, Milisen K, Liperoti R, et al. A retrospective, longitudinal study of factors associated with new antipsychotic medication use among recently admitted long-term care residents. BMC Geriatr. 2015;15:128.

8. Rhee Y, Csernansky JG, Emanuel LL, Chang CG, Shega JW. Psychotropic medication burden and factors associated with antipsychotic use: an analysis of a population-based sample of community-dwelling older persons with dementia. J Am Geriatr Soc. 2011;59(11):2100-7.
9. Rosenberg PB, Mielke MM, Han D, Leoutsakos JS, Lyketsos CG, Rabins PV, et al. The association of psychotropic medication use with the cognitive, functional, and neuropsychiatric trajectory of Alzheimer's disease. Int J Geriatr Psychiatr. 2012;27(12):1248-57.

10. Lucas JA, Chakravarty S, Bowblis JR, Gerhard T, Kalay E, Paek EK, et al. Antipsychotic medication use in nursing homes: a proposed measure of quality. Int J Geriatr Psychiatr. 2014;29(10):1049-61.

11. Gallini A, Andrieu S, Donohue JM, Oumouhou N, Lapeyre-Mestre M, Gardette V. Trends in use of antipsychotics in elderly patients with dementia: impact of national safety warnings. Eur Neuropsychopharmacol. 2014;24(1):95-104.

12. Pitkala KH, Juola AL, Hosia H, Teramura-Gronblad M, Soini H, Savikko N, et al Eight-year trends in the use of opioids, other analgesics, and psychotropic medications among institutionalized older people in Finland. J Am Med Dir Assoc. 2015;16(11):973-8.

13. Singh RR, Nayak R. Impact of FDA Black box warning on psychotropic drug use in noninstitutionalized elderly patients diagnosed with dementia: a retrospective study. J Pharm Pract. 2016;29(5):495-502.

14. Mort JR, Sailor R, Hintz L. Partnership to decrease antipsychotic medication use in nursing homes: impact at the state level. S D Med. 2014;67(2):67-9.

15. Reus VI, Fochtmann LJ, Eyler AE, Hilty DM, Horvitz-Lennon M, Jibson MD, et al. The American Psychiatric Association Practice Guideline on the Use of Antipsychotics to Treat Agitation or Psychosis in Patients With Dementia. Am J Psychiatry. 2016;173(5):543-6.

16. Jennum P, Baandrup L, Ibsen R, Kjellberg J. Increased all-cause mortality with use of psychotropic medication in dementia patients and controls: a population-based register study. Eur Neuropsychopharmacol. 2015;25(11): 1906-13.

17. Declercq T, Petrovic M, Azermai M, Vander Stichele R, De Sutter Al, van Driel ML, et al. Withdrawal versus continuation of chronic antipsychotic drugs for behavioural and psychological symptoms in older people with dementia. Cochrane Database Syst Rev. 2013;3:CD007726.

18. Azermai M, Petrovic M, Elseviers MM, Bourgeois J, Van Bortel LM, Vander Stichele RH. Systematic appraisal of dementia guidelines for the management of behavioural and psychological symptoms. Ageing Res Rev. 2012;11(1):78-86.

19. Plan-Alzheimer. Plan Gouvernemental Maladie d'Alzheimer. 2008-2012. http://www.cnsa.fr/documentation/plan_alzheimer_2008-2012-2.pdf.

20. Plan-Maladies-Neurodégénératives. Plan Gouvernemental Maladies Neurodégénératives. 2014-2019. http://social-sante.gouv.fr/IMG/pdf/plan_ maladies_neuro_degeneratives_def.pdf.

21. Spinney L. Alzheimer's disease funding and the French health system. Lancet Neurol. 2008:7(1):26-7.

22. Folstein MF, Folstein SE, McHugh PR. "Mini-mental test". A practical method for grading the cognitive state of patients for the clinician. J Psychiatry Res. 1975;12:189-98.

23. Le Duff F, Develay AE, Quetel J, Lafay P, Schuck S, Pradier C, et al. The 20082012 French Alzheimer plan: description of the national Alzheimer information system. J Alzheimers Dis. 2012;29(4):891-902

24. Child A, Clarke A, Fox C, Maidment I. A pharmacy led program to review antipsychotic prescribing for people with dementia. BMC Psychiatry. 2012;12:155.

25. Barnes TR, Banerjee S, Collins N, Treloar A, Mclntyre SM, Paton C. Antipsychotics in dementia: prevalence and quality of antipsychotic drug prescribing in UK mental health services. Br J Psychiatry. 2012;201(3):221-6.

26. Tuppin P, Cuerq A, Weill A, Ricordeau P, Allemand H. Alzheimer disease and other dementia in France: Identification, management and neuroleptic use (2007-2009). Rev Neurol. 2012;168(2):152-60.

27. Vida S, Monette J, Wilchesky M, Monette M, Friedman R, Nguyen A, et al. A long-term care center interdisciplinary education program for antipsychotic use in dementia: program update five years later. Int Psychogeriatr. 2012; 24(4):599-605.

28. Lustenberger I, Schupbach B, von Gunten A, Mosimann U. Psychotropic medication use in Swiss nursing homes. Swiss Med Wkly. 2011;141:w13254.

29. Rattinger GB, Burcu M, Dutcher SK, Chhabra PT, Rosenberg PB, Simoni-Wastila L, et al. Pharmacotherapeutic management of dementia across settings of care. J Am Geriatr Soc. 2013;61(5):723-33.

30. Alessi-Severini S, Dahl M, Schultz J, Metge C, Raymond C. Prescribing of psychotropic medications to the elderly population of a Canadian province: a retrospective study using administrative databases. PeerJ. 2013;1:e168.

31. Huber M, Kolzsch M, Rapp MA, Wulff I, Kalinowski S, Bolbrinker J, et al. Antipsychotic drugs predominate in pharmacotherapy of nursing home residents with dementia. Pharmacopsychiatry. 2012;45(5):182-8. 
32. Lopez OL, Becker JT, Chang YF, Sweet RA, Aizenstein H, Snitz B, et al. The long-term effects of conventional and atypical antipsychotics in patients with probable Alzheimer's disease. Am J Psychiatry. 2013;170(9):1051-8.

33. Afram B, Stephan A, Verbeek $H$, Bleijlevens MH, Suhonen R, Sutcliffe C, et al. Reasons for institutionalization of people with dementia: informal caregiver reports from 8 European countries. J Am Med Dir Assoc. 2014;15(2):108-16.

34. de Mauleon A, Sourdet S, Renom-Guiteras A, Gillette-Guyonnet S, Leino-Kilpi H, Karlsson S, et al. Associated factors with antipsychotic use in long-term institutional care in eight European countries: results from the RightTimePlaceCare study. J Am Med Dir Assoc. 2014;15(11):812-8.

35. Tartaglia MC, Hu B, Mehta K, Neuhaus J, Yaffe K, Miller BL, et al. Demographic and neuropsychiatric factors associated with off-label medication use in frontotemporal dementia and Alzheimer's disease. Alzheimer Dis Assoc Disord. 2014;28(2):182-9.

36. Wastesson JW, Ringback Weitoft G, Johnell K. Educational disparities in antipsychotic drug use among older people with and without dementia in Sweden. Acta Psychiatr Scand. 2015;132(1):20-8.

37. Bell JS, llomaki J, O'Connor DW. Why are more highly educated people with dementia less likely to be prescribed antipsychotics? Acta Psychiatr Scand. 2015;132(1):1-3.

38. Gulla C, Selbaek G, Flo E, Kjome R, Kirkevold O, Husebo BS. Multi-psychotropic drug prescription and the association to neuropsychiatric symptoms in three Norwegian nursing home cohorts between 2004 and 2011. BMC Geriatr. 2016; 16(1):115.

39. Kim H, Whall AL. Factors associated with psychotropic drug usage among nursing home residents with dementia. Nurs Res. 2006;55(4):252-8.

40. Franchi C, Tettamanti M, Marengoni A, Bonometti F, Pasina L, Cortesi L, et al. Changes in trend of antipsychotics prescription in patients treated with cholinesterase inhibitors after warnings from Italian Medicines Agency. Results from the EPIFARM-Elderly Project. Eur Neuropsychopharmacol. 2012; 22(8):569-77.

41. Sultana J, Fontana A, Giorgianni F, Pasqua A, Cricelli C, Spina E, et al. The effect of safety warnings on antipsychotic drug prescribing in elderly persons with dementia in the United Kingdom and Italy: a populationbased study. CNS Drugs. 2016:30(11):1097-109.

42. Taipale H, Koponen M, Tanskanen A, Tolppanen AM, Tiihonen J, Hartikainen S. High prevalence of psychotropic drug use among persons with and without Alzheimer's disease in Finnish nationwide cohort. Eur Neuropsychopharmacol. 2014;24(11):1729-37.

43. Lachaine J, Beauchemin C, Crochard A, Bineau S. The impact of memantine and cholinesterase inhibitor initiation for Alzheimer disease on the use of antipsychotic agents: analysis using the Regie de l'Assurance Maladie du Quebec database. Can J Psychiatry. 2013;58(4):195-200.

44. Martinez $C$, Jones RW, Rietbrock $\mathrm{S}$. Trends in the prevalence of antipsychotic drug use among patients with Alzheimer's disease and other dementias including those treated with antidementia drugs in the community in the UK: a cohort study. BMJ Open. 2013;3(1):1-12.

45. Reber KC, Piening S, Wieringa JE, Straus SM, Raine JM, de Graeff PA, et al. When direct health-care professional communications have an impact on inappropriate and unsafe use of medicines. Clin Pharmacol Ther. 2013;93(4): $360-5$.

46. Ballard C, Lana MM, Theodoulou M, Douglas S, McShane R, Jacoby R, et al. A randomised, blinded, placebo-controlled trial in dementia patients continuing or stopping neuroleptics (the DART-AD trial). PLoS Med. 2008;5(4):e76.

47. Sultana J, Trifiro G. Drug safety warnings: a message in a bottle. J Drug Dev Res. 2014; 1(1):1004.

48. Vandenbroucke JP, von Elm E, Altman DG, Gotzsche PC, Mulrow CD, Pocock SJ, et al. Strengthening the Reporting of Observational Studies in Epidemiology (STROBE): explanation and elaboration. Epidemiology. 2007;18(6):805-35.

\section{Submit your next manuscript to BioMed Central and we will help you at every step:}

- We accept pre-submission inquiries

- Our selector tool helps you to find the most relevant journal

- We provide round the clock customer support

- Convenient online submission

- Thorough peer review

- Inclusion in PubMed and all major indexing services

- Maximum visibility for your research

Submit your manuscript at www.biomedcentral.com/submit
( ) BioMed Central 